\title{
PENGARUH LEMBAR KERJA SISWA BERORIENTASI KETERAMPILAN GENERIK SAINS DENGAN MODEL PEMBELAJARAN DISCOVERY LEARNING TERHADAP PEMAHAMAN KONSEP KESETIMBANGAN KIMIA
}

\author{
Irma Ayu Virtayanti*, Abudarin**, Enny Wijayanti** \\ * Pendidikan Kimia, Staff Pengajar Program Sarjana Universitas Billfath Lamongan \\ ** Pendidikan Kimia, Staff Pengajar Program Pasca Sarjana Universitas Palangka Raya
}

\section{INFO ARTIKEL}

\section{Riwayat Artikel:}

Diterima: 17-12-2018

Disetujui: 19-12-2018

\section{Kata kunci:}

Kesetimbangan kimia LKS

keterampilan generik sains

discovery learning

\section{ABSTRAK}

Abstract: This study aims to determine the effect of the use of students workbooks oriented skills generic science in learning with discovery learning model of understanding the chemical equilibrium concept. The study was conducted at SMAN 4 Palangka Raya. The research used quasi experiment type pretest-postest control group design. Two classes of XI IPA were used in this study which consisted of a class as an experimental class that was taught by a learning-aided discovery learning model of a generic science-oriented skill-oriented student workbook and another class as a control class that was taught using a discovery learning model without a studentoriented worksheet generic science skills. Students workbook have 4 learning activities which contains 6 (six) generic science skills covering symbolic language, mathematical modelling, logic inference, logical consistency, causality and concept building. The instrument used in this study was validated by three expert validators and tested.The results showed that the understanding of the experimental class concept was higher than the control class students. Understanding the concept of the experimental class and the control class is different (the average value is 87.4 for the experimental class and is 69.6 for the control class). Independent Sample T-test results obtained by the Sig. (2-tailed) of $0.00<0.05$ means that there is a positive and significant effect of the use of KGS-oriented LKS on understanding students' chemical equilibrium concepts.

Abstrak: Penelitian ini bertujuan untuk mengetahui pengaruh penggunaan lembar kerja siswa berorientasi keterampilan generik sains dalam pembelajaran dengan model pembelajaran discovery learning terhadap pemahaman konsep kesetimbangan kimia. Penelitian dilakukan di SMAN 4 Palangka Raya. Rancangan penelitian yang digunakan adalah quasy experiment tipe pretest-postest control group design. Dua kelas XI IPA digunakan dalam penelitian ini yang terdiri dari satu kelas sebagai kelas eksperimen yang dibelajarkan dengan model pembelajaran discovery learning berbantuan lembar kerja siswa berorientasi keterampilan generik sains dan satu kelas lain sebagai kelas kontrol yang dibelajarkan menggunakan model pembelajaran discovery learning tanpa lembar kerja siswa berorientasi keterampilan generik sains. LKS berisi 4 kegiatan belajar yang memuat 6 (enam) keterampilan generik sains meliputi bahasa simbolik, pemodelan matematik, inferensi logika, konsistensi logika, hubungan sebab akibat dan membangun konsep. Instrumen yang digunakan dalam penelitian ini divalidasi oleh tiga orang validator ahli dan diujicobakan. Pembelajaran penemuan (discovery learning) berbantuan LKS berorientasi KGS dapat meningkatkan hasil belajar siswa materi kesetimbangan kimia. Hasil penelitian menunjukkan pemahaman konsep kelas eksperimen lebih tinggi dibandingkan dengan siswa kelas kontrol. Pemahaman konsep kelas eksperimen dan kelas kontrol berbeda (nilai rata-rata sebesar 87,4 untuk kelas eksperimen dan sebesar 69,6 untuk kelas kontrol). Hasil Uji Independent Sample T-test yang diperoleh nilai Sig. (2-tailed) sebesar $0,00<0,05$ artinya ada pengaruh yang positif dan signifikan dari penggunaan LKS berorientasi KGS terhadap pemahaman konsep kesetimbangan kimia siswa. 
Virtayanti, Pengaruh Lembar Kerja ...

\section{Alamat Korespondensi:}

Irma Ayu Virtayanti,

Pendidikan Kimia

Universitas Billfath Lamongan

Kompleks PP Al-Fattah, Desa Siman, Kecamatan Sekaran, Kabupaten Lamongan, Jawa Timur

E-mail: irma.virtayanti@gmail.com

Ilmu kimia merupakan bagian dari sains yang mempelajari tentang struktur, susunan, sifat, perubahan serta energi yang menyertainya. Sebagai bagian dari ilmu sains, kimia merupakan salah satu mata pelajaran yang sampai saat ini dianggap sulit untuk dipahami. Selain itu, pelajaran kimia juga memiliki karakteristik tersendiri dan memerlukan keterampilan dalam memecahkan masalah-masalah ilmu kimia yang berupa teori, konsep, hukum dan fakta. Permasalahan yang terjadi di lapangan pada materi konsep kesetimbangan kimia guru lebih dominan menggunakan metode ceramah, sehingga materi yang diterima siswa hanya berdasarkan penyampaian guru. Siswa tidak menemukan sendiri konsep yang seharusnya dicapai. Siswa juga tidak dilatih untuk mengembangkan kemampuan berfikir yang dimiliki, terutama kemampuan kemampuan berfikir tingkat tinggi (Higher Order Thinking $=$ HOT)

Pembelajaran sains ditujukan bukan hanya agar siswa memahami pengetahuan alam tetapi juga untuk mengembangkan kemampuan berfikir, terutama kemampuan berfikir tingkat tinggi (Higher Order Thinking = HOT). Pengembangan HOT dilakukan baik dalam proses pembelajaran maupun dalam evaluasi pembelajaran dengan tujuan agar dapat mengembangkan kemampuan berpikir yang dimiliki siswa secara optimal Gallagher, J.J., (2007). Pengembangan HOT dalam pembelajaran mendorong siswa dapat membedakan ide atau gagasan secara jelas, berargumen dengan baik, mampu memecahkan masalah, mampu mengkonstruksi penjelasan, mampu berhipotesis dan memahami hal-hal kompleks menjadi lebih jelas Haryanto (2011).

Pada pembelajaran sains, berpikir tingkat tinggi (HOT) mencakup sejumlah keterampilan-keterampilan berpikir yang disebut keterampilan generik sains (KGS). KGS mencakup keterampilan dalam melakukan pengamatan langsung atau tak langsung, bahasa simbolik, inferensi logika, pendekatan matematik, dan membangun konsep Liliasari (2007).

Pembelajaran dalam perspektif teori konstruktivistik adalah proses dimana siswa aktif secara mental mengonstruksi pengetahuan baru yang dilandasai oleh struktur kognitif siswa berdasarkan pengalaman. Pendekatan konstruktivistik merupakan pembelajaran yang menekankan pada peran aktif siswa dalam membangun pemahaman dan memberi makna terhadap informasi dan peristiwa yang dialami Daryanti, E.P., dkk. (2015).

Metode yang relevan dengan teori konstruktivistik antara lain metode yang dikembangkan oleh Jerome Bruner yaitu pembelajaran penemuan (discovery learning). Langkah-langkah pembelajaran penemuan (discovery learning) berisi; a. Stimulation (stimulasi/memberikan rangsangan); b. Problem statement (pernyataan/identifikasi masalah); c. Data collection (pengumpulan data); d. Data processing (pengolahan data); e. Verification (pembuktian); dan f. Generalization (menarik kesimpulan/generalisasi). Menurut Burner dalam proses pembelajaran siswa hendaknya secara aktif menggunakan konsep-konsep atau prinsip-prinsip yang telah mereka kuasai dan melakukan penyelidikan atau eksperimen untuk menemukan konsep-konsep dan prinsip-prinsip yang baru Trianto (2010).

Perlunya panduan belajar agar siswa dapat melakukan aktivitas belajar penemuan secara efektif dan efesien. Panduan belajar tersebut dapat dikemas misalnya dalam bentuk Lembar Kerja Siswa (LKS). LKS merupakan salah satu sarana untuk menuntun, membimbing, dan mengarahkan siswa agar kegiatan pembelajaran berlangsung secara efektif. Dengan menggunakan LKS akan terjadi interaksi yang efektif antara siswa dan guru sehingga dapat meningkatkan aktifitas siswa dalam melakukan pembelajaran penemuan (discovery learning) Trianto (2010).

LKS berorientasi keterampilan generik sains adalah LKS yang dirancang sedemikian rupa untuk memandu siswa dalam belajar agar memperoleh pengetahuan dan sekaligus meningkatkan KGS secara optimal. Dalam LKS berorientasi KGS, setiap aktivitas belajar untuk memperoleh pengetahuan baru dilakukan dengan proses berfikir yang mengacu kepada komponen keterampilan generik sains.

Pada penelitian ini LKS berorientasi KGS digunakan untuk topik pembelajaran kesetimbangan kimia. Materi kesetimbangan kimia melatih kemampuan menyusun persamaan reaksi kesetimbangan seperti $\mathrm{HCl},(\mathrm{s}),(\mathrm{g})$, dan + secara tepat untuk menjelaskan suatu reaksi kesetimbangan ke dalam bentuk persamaan kimia keterampilan bahasa simbolik. Kemampuan menjelaskan tentang prinsip azas Le Chatelier memerlukan keterampilan membangun konsep. Kemampuan menganalisis data untuk mengidentifikasi keteraturan memerlukan keterampilan konsistensi 
logika. Kemampuan menjelaskan pergeseran kesetimbangan kimia memerlukan keterampilan inferensi logika dan hubungan sebab akibat. Keterampilan pemodelan matematik sangat diperlukan dalam menghitung harga Kc berdasarkan harga Kp dalam materi kesetimbangan kimia.

Bertolak dari fenomena di atas, penelitian ini mengkaji pengaruh penggunaan lembar kerja siswa berorientasi keterampilan generik sains dalam pembelajaran dengan model pembelajaran discovery learning terhadap pemahaman konsep kesetimbangan kimia.

\section{METODE}

Rancangan eksperimental semu (Quasy Experimental Design) dengan pretest and posttest control group adalah desain yang digunakan dalam penelitian ini. Penelitian ini bertujuan untuk menguji perbedaan pemahaman konsep pada kelas eksperimen dan kelas kontrol. Penelitian dilaksanakan di SMA Negeri 4 Palangka Raya. Kelas eksperimen yang terpilih adalah kelas XI IPA 4, sedangkan kelas kontrol yang terpilih adalah kelas XI IPA 5. Penentuan kelas eksperimen maupun kelas kontrol dilakukan secara acak.

Instrumen yang digunakan meliputi LKS berorientasi KGS dan soal tes pemahaman konsep berupa soal uraian objektif yang dikembangkan dengan mengacu pada indikator pembelajaran untuk materi kesetimbangan kimia. Sebelum digunakan di kelas, LKS divalidasi oleh 3 orang ahli, yaitu ahli bahasa, ahli kimia, dan ahli pendidikan. Skor hasil penilaian ahli digunakan untuk mengitung koefisien validitas isi menggunakan formula Aiken's V Aiken, L.R. (1985).

Uji normalitas dilakukan terhadap data pretest dan data posttest hasil belajar melalui pemahaman konsep siswa, yang telah didapat dari hasil pembelajaran pada kelas kontrol dan kelas eksperimen. Untuk melihat peningkatan hasil belajar siswa, maka data hasil prestest dan posttest pada kelas kontrol dan kelas eksperimen harus terdistribusi normal. Pada penelitian ini uji normalitas yang digunakan adalah uji kolmogrov-smirnov. Data dikatakan memenuhi asumsi normalitas atau terdistribusi normal jika pada kolmogorov-smirnov nilai sig. $>0.05$ sebaliknya data yang nilai sig. $<0.05$ tidak terdistribusi normal (Arikunto, 2012).

Setelah dilakukan uji normalitas, selanjutnya dilakukanlah uji Independent Sample T-Test. Uji ini dilakukan untuk membandingkan dua sampel yang berbeda (bebas). Independent Sample T-Test digunakan untuk mengetahui ada atau tidaknya peningkatan rata-rata antara dua kelompok sampel yang tidak berhubungan. Hipotesis berupa Ho : tidak ada pengaruh yang positif dan signifikan dari penggunaan LKS berorientasi KGS terhadap pemahaman konsep kesetimbangan kimia siswa; Ha : ada pengaruh yang positif dan signifikan dari penggunaan LKS berorientasi KGS terhadap pemahaman konsep kesetimbangan kimia sisw. Analisis ini digunakan untuk mengetahui diterima atau tidaknya hipotesis yang telah dibuat. Kriteria pengujiannya yaitu jika probabilitas (Asymp.Sig) < 0,05, maka Ho ditolak dan jika probabilitas (Asymp.Sig) > 0,05, maka Ho diterima (Priyatno, 2010).

\section{HASIL}

Dari hasil perhitungan diperoleh koefisien validitas isi sebesar 0,92 yang berarti bahwa LKS valid atau memadai dengan sedikit revisi pada beberapa bagian. Hasil validasi soal didapatkan bahwa soal dapat digunakan untuk mengukur pemahaman konsep kesetimbangan kimia dengan koefisien validitas isi (Aiken's V) sebesar 0,87. Soal tes juga dilakukan uji coba empiris untuk mengukur daya beda, tingkat kesukaran dan reabilitas. Seluruh soal (13 butir) termasuk dalam kategori dengan tingkat kesukaran sedang dan daya pembeda cukup. Hal ini berarti soal layak dan tidak perlu di revisi. Hasil dari uji coba empiris didapatkan bahwa nilai reliabilitas adalah 0,89 berarti bahwa tes dengan nilai Cronbach'Alpha lebih besar dari $\mathrm{r}_{\text {tabel }}$ dinyatakan reliabel (konsisten/ajeg). Setelah digunakan, dilakukan uji prasyarat analisis yang terdiri dari uji normalitas dan uji homogenitas terhadap data yang diperoleh dengan bantuan SPSS 20.0. selanjutnya dianalisis menggunakan uji-t (sample independent t-test).

Hasil uji normalitas (kolmogrov-smirnov) pada data pretest menunjukkan nilai 1,413 > 0,05 yang berarti bahwa data berdistribusi normal. Selanjutnya dilakukan uji Q-Q Plot. 


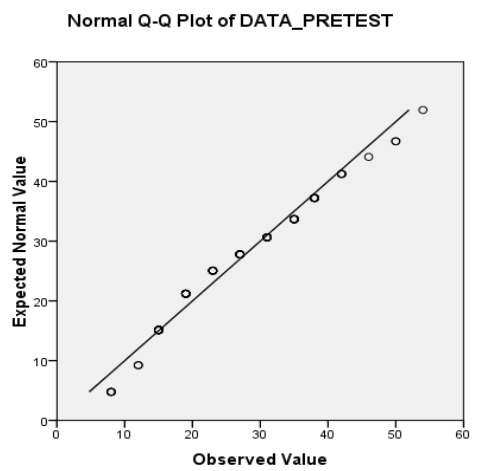

\section{Gambar 1. Grafik Uji Q-Q plot Data pretest}

Gambar 1. menunjukkan bahwa garis diagonal dalam grafik ini menggambarkan keadaan ideal dari data yang mengikuti distribusi normal. Titik-titik di sekitar garis adalah keadaan data yang diuji. Kebanyakan titik-titik berada sangat dekat dengan garis atau bahkan menempel pada garis, maka dapat disimpulkan data berdistribusi normal.

Hasil uji normalitas (kolmogrov-smirnov) pada data posttest menunjukkan nilai 1,212 > 0,05 yang berarti bahwa data berdistribusi normal. Selanjutnya dilakukan uji Q-Q Plot.

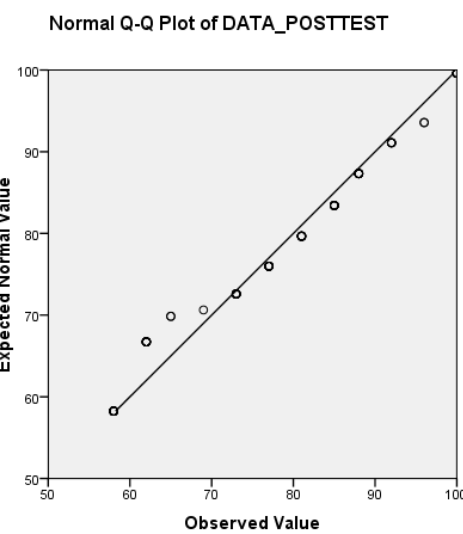

Gambar 2. Grafik Uji Q-Q plot Data posttest

Gambar 2. menunjukkan bahwa garis diagonal dalam grafik ini menggambarkan keadaan ideal dari data yang mengikuti distribusi normal. Titik-titik di sekitar garis adalah keadaan data yang diuji. Kebanyakan titik-titik berada sangat dekat dengan garis atau bahkan menempel pada garis, maka dapat disimpulkan data berdistribusi normal.

Hasil uji homogenitas pada data pretest menunjukkan nilai 0,099>0,05 yang berarti bahwa varians kelompok pretest kelas eksperimen dan pretest kelas kontrol adalah sama atau homogen. Sedangkan, hasil uji homogenitas pada data posttest menunjukkan nilai 0,085 >0,05 yang berarti bahwa varians kelompok posttest kelas eksperimen dan posttest kelas kontrol adalah sama atau homogen.

Data pemahaman konsep kesetimbangan kimia diperoleh dari hasil pretest. Pemerolehan nilai siswa pada kelas eksperimen dan kelas kontrol disajikan pada Tabel 1. 
KARANGAN: Jurnal Kependidikan, Pembelajaran, dan Pengembangan, Vol 01, No 01, Bln Feb, Thn 2019, Hal 17-23

Tabel 1. Data Nilai Siswa Kelas Eksperimen dan Kelas Kontrol

\begin{tabular}{lllll}
\hline \multicolumn{1}{c}{ Kelas } & $\mathbf{N}$ & \multicolumn{2}{c}{ Nilai } & $\begin{array}{c}\text { NIlai } \\
\text { Rata- } \\
\text { Rata }\end{array}$ \\
\cline { 3 - 4 } & & Minimal & Maksimal & 32 \\
Kontrol & 40 & 15 & 46 & 20 \\
eksperimen & 40 & 8 & 38 & \\
\hline
\end{tabular}

Berdasarkan data Tabel 1. hasil belajar siswa pada saat pretest di kelas kontrol nilai siswa yang terendah adalah 15 , sedangkan di kelas eksperimen nilai siswa yang terendah adalah 8. Dan hasil belajar siswa pada saat pretest di kelas kontrol nilai siswa yang tertinggi adalah 46, sedangkan di kelas eksperimen nilai siswa yang tertinggi adalah 38. Hasil belajar siswa rata-rata pad akelas kontrol adalah sebesar 32, sedangkan kelas eksperimen sebesar 20.

Data pemahaman konsep kesetimbangan kimia diperoleh dari hasil posttest. Pemerolehan nilai siswa pada kelas eksperimen dan kelas kontrol disajikan pada Tabel 2.

\begin{tabular}{|c|c|c|c|c|}
\hline \multirow[t]{2}{*}{ Kelas } & \multirow[t]{2}{*}{$\mathbf{N}$} & \multicolumn{2}{|c|}{ Nilai } & \multirow{2}{*}{$\begin{array}{l}\text { NIlai } \\
\text { Rata- } \\
\text { Rata }\end{array}$} \\
\hline & & Minimal & Maksimal & \\
\hline $\begin{array}{l}\text { Kontrol } \\
\text { eksperimen }\end{array}$ & $\begin{array}{l}40 \\
40\end{array}$ & $\begin{array}{l}58 \\
73\end{array}$ & $\begin{array}{l}92 \\
100\end{array}$ & $\begin{array}{l}69,6 \\
87,4\end{array}$ \\
\hline
\end{tabular}

Berdasarkan data Tabel 2. hasil belajar siswa pada saat postest di kelas kontrol nilai siswa yang terendah adalah 58, sedangkan di kelas eksperimen nilai siswa yang terendah adalah 73. Dan hasil belajar siswa pada saat postest di kelas kontrol nilai siswa yang tertinggi adalah 100, sedangkan di kelas eksperimen nilai siswa yang tertinggi adalah 92.

Hasil belajar siswa yang menggunakan pembelajaran penemuan (discovery learning) berbantuan LKS berorientasi KGS sebesar 87,4, sedangkan hasil belajar siswa yang menggunakan pembelajaran penemuan (discovery learning) tanpa LKS berorientasi KGS sebesar 69,6.

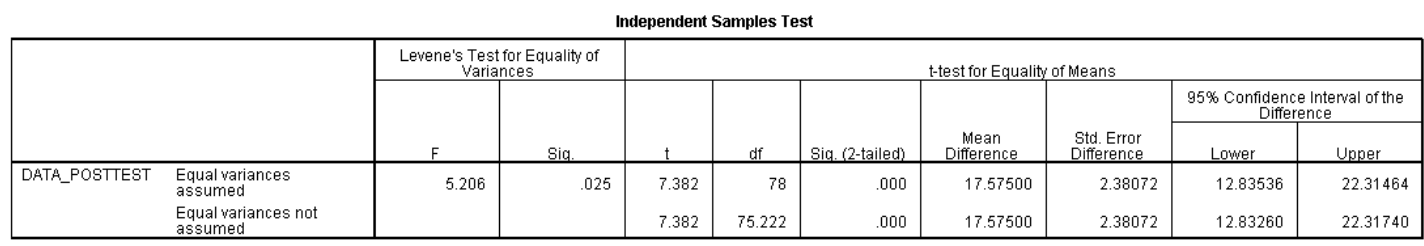

Gambar 3. Hasil uji-t (sample independent t-test) 
Berdasarkan Gambar 3. hasil uji-t (sample independent t-test) diatas maka nilai Sig. Lebih kecil dari 0,05 maka $\mathrm{H}_{0}$ ditolak, artinya ada pengaruh yang positif dan signifikan dari penggunaan LKS berorientasi KGS terhadap pemahaman konsep kesetimbangan kimia siswa.

\section{PEMBAHASAN}

Berdasarkan data hasil hasil uji-t (sample independent t-test) diatas maka nilai Sig. lebih kecil dari 0,05 maka $\mathrm{H}_{0}$ ditolak, artinya ada pengaruh yang positif dan signifikan dari penggunaan LKS berorientasi KGS terhadap pemahaman konsep kesetimbangan kimia siswa. Hal ini dikarenakan siswa yang diberi pembelajaran penemuan (discovery learning) berbantuan LKS berorientasi KGS memiliki kesempatan untuk dapat menemukan konsep oleh dirinya sendiri, selain itu juga siswa lebih terlatih berpikir tingkat tinggi (HOT) dengan meningkatkan KGS yang dimilikinya.

Terdapat perbedaan hasil belajar antara siswa kelas eksperimen dan kelas kontrol. Hal ini juga dapat dibuktikan dengan pengujian hipotesis, yakni $t_{0}$ yang diperoleh lebih besar dari $t_{\text {tabel }}$ yaitu, 1,99< 7,39> 2,64. Karena $t_{0}$ yang diperoleh lebih besar dari $\mathrm{t}_{\text {tabel}}$, maka dapat dinyatakan $\mathrm{H}_{0}$ ditolak dan $\mathrm{H}_{\mathrm{a}}$ di terima. Sehingga, dapat disimpulkan bahwa pemahaman konsep kesetimbangan kimia siswa yang menggunakan pembelajaran penemuan (discovery learning) berbantuan LKS berorientasi KGS lebih efektif.

Hasil penelitian yang diperoleh selaras dengan hasil penelitian Frantius (2016) tentang pengembangan modul konsep asam basa berorientasi KGS yang menyimpulkan bahwa peningkatan KGS dapat dilihat dari $N$-gain score yang diperoleh tiap komponen KGS berada pada kategori sedang dan tinggi. Demikian pula, Sapotrini (2008) melakukan penelitian tentang peningkatan KGS bagi mahasiswa melalui perkuliahan praktikum kimia analisis instrument berbasis inkuiri menyimpulkan bahwa penerapan model pembelajaran praktikum kimia analisis instrumen berbasis inkuiri mampu meningkatkan penguasaan KGS calon guru kimia sampai pada tingkat pencapaian harga $\mathrm{N}$-gain kategori tinggi dan sedang. Selain itu, Virtayanti (2017) tentang pengembangan LKS berorientasi KGS dalam pembelajaran kesetimbangan kimia yang menyimpulkan bahwa peningkatan pemahaman konsep kesetimbangan kimia siswa sebelum dan sesudah pembelajaran termasuk dalam kategori tinggi dengan rata-rata $\mathrm{N}$-Gain sebesar 0,85 .

\section{SIMPULAN DAN SARAN}

\section{Simpulan}

Pembelajaran penemuan (discovery learning) berbantuan LKS berorientasi KGS dapat meningkatkan hasil belajar siswa materi kesetimbangan kimia. Hasil penelitian menunjukkan pemahaman konsep kelas eksperimen lebih tinggi dibandingkan dengan siswa kelas kontrol. Pemahaman konsep kelas eksperimen dan kelas kontrol berbeda (nilai rata-rata sebesar 87,4 untuk kelas eksperimen dan sebesar 69,6 untuk kelas kontrol). Hasil Uji Independent Sample T-test yang diperoleh nilai Sig. (2-tailed) sebesar 0,00 0,05 artinya ada pengaruh yang positif dan signifikan dari penggunaan LKS berorientasi KGS terhadap pemahaman konsep kesetimbangan kimia siswa.

\section{Saran}

Hasil penelitian menunjukkan bahwa pembelajaran dengan menggunakan LKS berorientasi KGS memberikan pemahaman konsep dan KGS yang baik. Oleh karena itu, LKS berorientasi KGS merupakan sumber belajar alternatif yang dapat digunakan dalam pembelajaran kimia. Sebaiknya guru kimia dapat mengembangkan LKS berorientasi KGS untuk pembelajaran yang ditujukan untuk meningkatkan pemaahaman konsep dan sekaligus meningkatkan kemampuan berpikir siswa.

\section{UCAPAN TERIMA KASIH}

Terima kasih disampaikan kepada Yenihayati, S.Pd., M.Pd, (Kepala Sekolah SMAN 4 Palangka Raya). 
KARANGAN: Jurnal Kependidikan, Pembelajaran, dan Pengembangan, Vol 01, No 01, Bln Feb, Thn 2019, Hal 17-23

\section{DAFTAR RUJUKAN}

Aiken, L.R. 1985. Three Coefficients for Analyzing the Reliability of Single Items or Questionnaires. Educational and Psychological Measurement.

Daryanti, E.P., Rinato, Y., Dwiastuti, S., 2015, Peningkatan Kemampuan Penalaran Ilmiah Melalui Model Pembelajaran Inkuiri Terbimbing pada Materi Sistem Pernapasan Manusia. Jurnal Pendidikan Matematika dan Sains. 3, 163-168

Frantius, Deklin. 2016. Pengembangan Modul Konsep Asam Basa Berorientasi Keterampilan Generik Sains. Tesis. Universitas Negeri Malang.

Gallagher, J.J., 2007. Teaching Science for Understanding: A Practical Guide for School Teachers. Person Merril Prentice Hall. New Jersey.

Haryanto. 2011. Evaluasi Pembelajaran pada Sekolah Bertaraf Internasional. Makalah, disampaikan pada Workshop Pengembangan Instrumen Evaluasi pada Sekolah Bertaraf Internasiona, Jurusan Kimia, FMIPA UNNES, tanggal 7 Mei 2011.

Liliasari. 2007. Scientific Concepts and Generic Science Skills Relationship In The $21^{\text {st }}$ Century Science Education. Seminar Proceeding of The First Inernational Seminar of Science Education. 27 Oktober 2007. Bandung. 1318.

Priyatno, D. 2010. Teknik Mudah dan Cepat Melakukan Analisis Data Penelitian dengan SPSS dan Tanya Jawab Ujian Pendadaran. Yogyakarta. Gaya Media

Saptorini. 2008. Peningkatan Keterampilan Generik SAINS bagi Mahasiswa melalui Perkuliahan Praktikum Kimia Analisis Instrumen Berbasis Inkuiri. Jurnal Inovasi Pendidikan Kimia. Vol. II, no. I, Tersedia online di http://journal.unnes.ac.id/nju/index.php/JIPK/article/view/1218/1174.

Trianto. 2010. Model Pembelajaran Terpadu. Surabaya: Bumi Aksara.

Trianto. 2010. Mendesain Model Pembelajaran Inovatif-Progresif (Konsep, Landasan, dan Implementasinya pada Kurikulum Tingkat Satuan Pendidikan (KTSP)). Jakarta: Kencana

Virtayanti,I.A, Abudarin, \& Wijayanti, E. 2017, Pengembangan Lembar Kerja Siswa Berorientasi Keterampilan Generik Sains Dalam Pembelajaran Kesetimbangan Kimia (Studi di SMAN 4 Palangka Raya). Prosiding Seminar Nasional Kimia dan Pendidikan Kimia, FKIP, Universitas Sebelas Maret, 22 April 2017. 92-99. Surakarta: Universitas Sebelas Maret. 